ECOLOGY AND SOCIETY

Home | Archives | About | Login | Submissions | Notify | Contact | Search

ES HOME > VOL. 1, NO. 2 > ART. 2

Copyright (c) 1997 by The Resilience Alliance* ${ }^{*}$

Walker, B., and W. Steffen. 1997. An overview of the implications of global change for natural and managed terrestrial ecosystems. Conservation Ecology [online]1(2): 2. Available from the Internet. URL: http://www.consecol.org/vol1/iss2/art2/

A version of this article in which text, figures, tables, and appendices are separate files may be found by following this link.

\title{
Synthesis
}

\section{An Overview of the Implications of Global Change for Natural and Managed Terrestrial Ecosystems*}

Brian Walker $^{1}$ and Will Steffen $^{1}$

\section{${ }^{1}$ CSIRO Wildlife and Ecology and GCTE Core Project Office}

- Abstract

- Introduction

- Ecosystem Responses

- The Terrestrial Carbon Cycle

- Living with Global Change

- Concluding Comment

- Responses to this article

- Acknowledgments

- Literature Cited

\section{ABSTRACT}

Global change is the net effect of individual and interactive effects of changes in land use, atmospheric composition, biological diversity, and climate. A synthesis of the past six years' activities of the Global Change and Terrestrial Ecosystems project of the IGBP (International Geosphere-Biosphere Programme) deals with global change effects as ecosystem responses and living with global change. Ecosystem responses are considered in terms of changes in function and vegetation composition/structure. Field experiments of elevated $\mathrm{CO}_{2}$ effects on aboveground biomass show, on average, a positive effect on biomass, ranging from $-20 \%$ to $+80 \%$. Some early predictions of $\mathrm{CO}_{2}$ effects ( $\mathrm{C}_{3}$ vs. $\mathrm{C}_{4}$ plants, $\mathrm{N}$-fixers, $\mathrm{C}: \mathrm{N}$ in litter) are not generally supported, and it is necessary to consider the interactive effects of changes in $\mathrm{CO}_{2}$, temperature, and nitrogen. Dynamic global vegetation models involving transient changes show that biomes will not shift as intact entities. Significant changes in vegetation, especially in high latitudes, are likely over the next century, and changes in disturbance regimes will be most important. Based on forecast changes in land use, vegetation structure, and ecosystem physiology, the terrestrial biosphere will probably become a source rather than a sink for carbon over the next century.

Because of land use change, the terrestrial biosphere of the 21st century will probably be further impoverished in species richness and substantially reorganized. More natural ecosystems will be in an early successional state or converted to production systems. The biosphere will be generally weedier and structurally simpler, with fewer areas in an ecologically complex old-growth state.

Temperate crop production will probably increase slightly because of $\mathrm{CO}_{2}$ increases $(5-7 \%$ for wheat for average field conditions), but crop production in the tropics may decline in some areas. Land use change will have the greatest effect on pastures and rangelands; due to a required $>2 \%$ annual increase in crop production to meet the 
expanding human population, there will be increased incursion of cropland into rangelands.

Submitted: October 24, 1997. Accepted: November 19, 1997.

KEY WORDS: agriculture; biomes; carbon dioxide; climate; dynamics; ecosystem functioning; global change; impacts; land use; terrestrial biosphere; vegetation changes.

\section{INTRODUCTION}

The starting point for assessing the future of the world's natural and managed terrestrial ecosystems is the recognition that global change is much more than climate change. It is the net effect of the individual and interactive effects of changes in land use, atmospheric composition, biological diversity, and climate change. In regard to the status of these four major drivers of global change, we note that:

- Atmospheric composition is changing. The increases in $\mathrm{CO}_{2}$ and other greenhouse gases are undisputed and, with the exception of CFCs, they will continue to rise for at least the next several decades.

- Land use is changing. This involves conversions from one type of land cover to another, as well as changes in management practices (such as fertilization, changes from harrowing to zero-tillage, etc.). It also includes changes in availability of surface water and river flows.

- Biodiversity is declining in most regions of the world.

- Climate is probably changing. The Intergovernmental Panel on Climate Change (IPCC) 1995 assessment (IPCC WGI 1995) concludes that human-induced change in the world's climate is detectable.

Underlying all four drivers are undisputed and dramatic changes in the human population (Fig. 1), in terms of increases in numbers, movements, per capita consumption of natural resources, and technological capacity to access resources.

Fig 1. Increase in human population.

\section{Populatlon (BIIllons of people)}

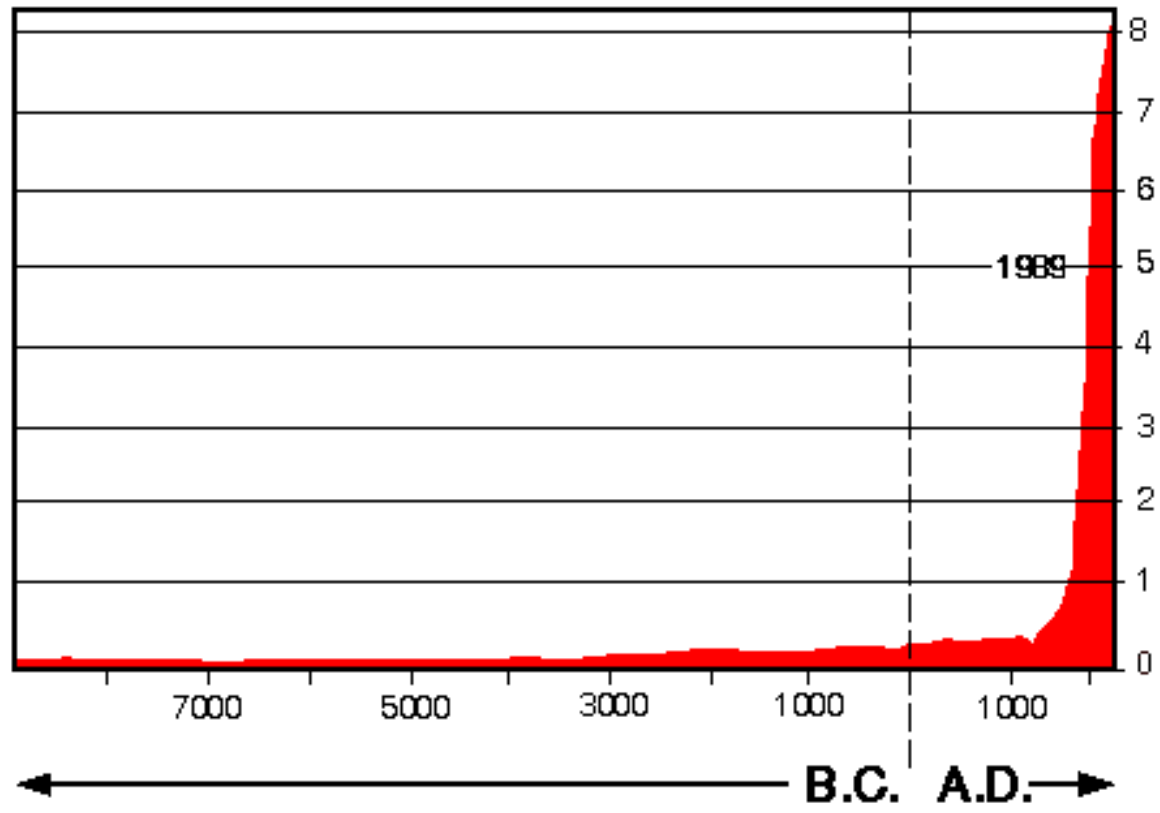

The statistics are widely known, but it is important to recognize their significance and to emphasize the following points. Although the most recent United Nations estimates indicate a slight lessening of the rate of increase beyond the middle of the next century, the human population will continue to grow at current rates until then. All assessments agree that there will be no slowing of the population increase through 2050. The U.N. median (most likely) estimate for 2050 is 9.4 billion, an increase through the 1990 s of some $80 \times 10^{6}$ people per year. The 
implications of population change become clearer when one recognizes that the human population has increased threefold since 1900, and that this has been accompanied by a 20-fold increase in the world economy, a 30-fold increase in fossil fuel consumption, and a 50 -fold increase in industrial production. The next 50 years will see another twofold increase in human numbers and a five- to 10 -fold increase in the world economy.

As a consequence of the inexorable population increase, crop yields will have to increase by $>2 \%$, consistently, every year; before the middle of the next century, they will have to increase by $>250 \%$. The combination of economic developments and concurrent advances in technology will result in an increased per capita consumption of natural resources. The ecological consequences of these developments will inevitably include further intensification of land use practices and further conversion of natural vegetation to cultivated lands, mostly in areas that are currently marginal for cropping.

Returning to our opening point, changes in atmospheric composition and climate will influence land use. These land use changes will feed back, directly, to both atmospheric composition and climate; the net effects of all these changes (collectively referred to as global change) will be their combined individual and interactive effects.

This paper is based on a synthesis of the first six years of the International Geosphere-Biosphere Programme's (IGBP) Global Change and Terrestrial Ecosystems (GCTE) Project. The synthesis was carried out by $>30$ scientists, including the GCTE Scientific Steering Committee (SSC), and was based on a large body of research (the GCTE Research Program) involving >1000 scientists and technicians in 44 countries around the world. The synthesis (Walker et al., in press), is due to appear in early 1998. The format of the paper follows a presentation by the first author of the Executive Summary of the synthesis at the annual meeting of the Ecological Society of America, in August 1997. We present here the main findings of the synthesis in three sections: ecosystem responses, the terrestrial carbon cycle, and living with global change.

\section{ECOSYSTEM RESPONSES}

Ecosystem responses are most conveniently considered under two headings: ecosystem functioning and vegetation change. The first deals with terrestrial ecosystem interactions with global change, given any particular state of an ecosystem. The second deals with changes in the state of the ecosystem (i.e., in the structure and composition of vegetation) due to global change.

\section{Ecosystem functioning}

Much of the initial work on ecosystem physiology has focused on the ecosystem-level effects of elevated $\mathrm{CO}_{2}$ and on its interactions with other factors. The emerging understanding can be summarized as follows:

- Most whole ecosystems exposed to double $\mathrm{CO}_{2}$ concentrations show higher peak-season net carbon uptake than those growing at ambient $\mathrm{CO}_{2}$ concentration. For grasslands, aboveground productivity increased by an average of $16 \%$ across all experiments, although the responses of individual grassland communities varied widely, with some being negative (see Fig. 2). The variation in community responses reflects variation in their component species, the interactive effects among species, and the highly interactive nature of the $\mathrm{CO}_{2}$ response with other environmental factors such as water, nutrient availability, and temperature.

Fig. 2. Stimulation of aboveground biomass of herbaceous systems by elevated $\mathrm{CO}_{2}$, with and without addition of nitrogen. The mean value indicated is for all points, both with and without nitrogen addition. 


\section{Herbaceous systems}

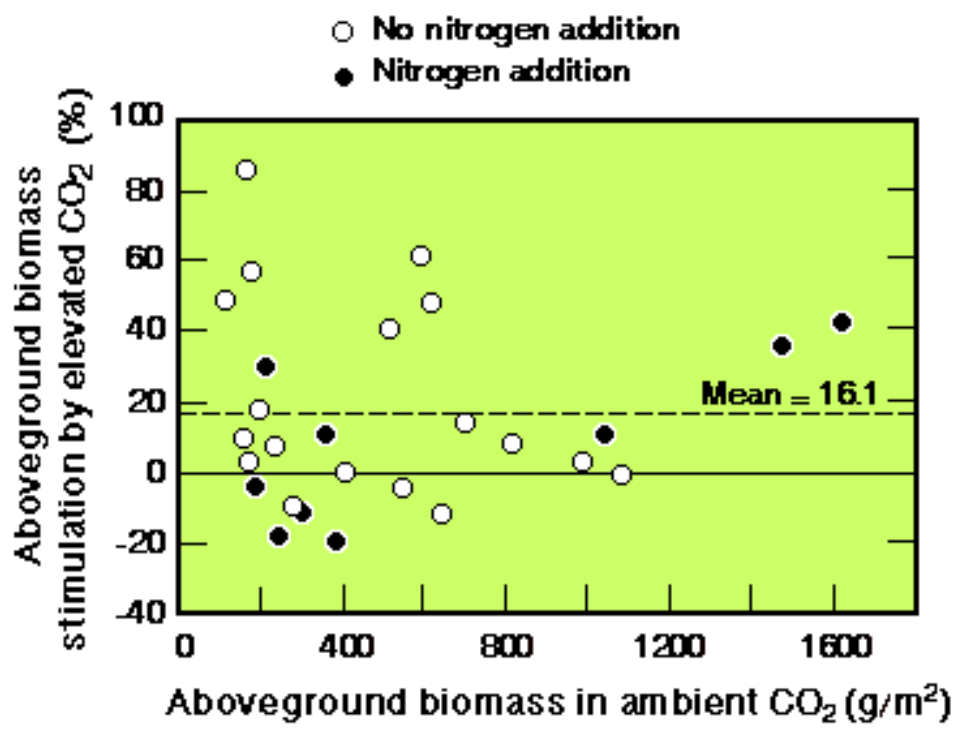

- Cold ecosystems, such as tundra and alpine grassland, are the least responsive to elevated $\mathrm{CO}_{2}$, in some cases showing no growth response and complete acclimation of peak-season gas exchange after a few years. Faster growth in juvenile trees does not indicate whether forests as a whole will sequester more carbon or not.

-Two earlier predictions about responsiveness to elevated $\mathrm{CO}_{2}$ were that (1) $\mathrm{C}_{4}$ species will respond less than $\mathrm{C}_{3}$ species; and (2) species with nitrogen-fixing symbionts will show a larger biomass response. In general, neither of these predictions has been consistently confirmed in ecosystem studies.

- Also contrary to earlier predictions, litter from plants grown under elevated $\mathrm{CO}_{2}$ does not necessarily decompose more slowly. The ratio of $\mathrm{C}: \mathrm{N}$ in litter from plants grown under elevated $\mathrm{CO}_{2}$ generally is not higher than that from plants grown in ambient $\mathrm{CO}_{2}$, although there is a great deal of variation among species.

- Elevated $\mathrm{CO}_{2}$ generally increases the allocation of photosynthate to roots, which increases the capacity and/or activity of belowground carbon sinks. Models suggest that some of the increased capacity of belowground sinks may lead to increased long-term soil carbon sequestration, although strong empirical evidence is still lacking.

- Herbaceous plants exposed to elevated $\mathrm{CO}_{2}$ show a reduction in stomatal conductance, which commonly results in reduced loss of soil moisture. This increase in water availability is the dominant driver for increased net carbon uptake in water-limited grassland systems.

- There is also a reduction in stomatal conductance in tree seedlings exposed to elevated $\mathrm{CO}_{2}$, but this does not seem to be the case for mature trees (forests), based on current experimental data sets. Control of hydraulic conductivity in big trees evidently is much less dependent on stomatal conductivity.

- Indirect temperature effects will be more significant than direct effects. Direct effects of increased air temperature on plant growth may be smaller than is often expected because of thermal acclimation. However, there will probably be developmental acceleration and stimulation of litter decomposition. Indirect temperature effects are mainly associated with warming of permafrost in the high latitudes, which may cause thermokarst expansion, substantial changes in species composition (toward woody shrubs rather than mosses), and increased nutrient availability.

- In some forests, nitrogen deposition is associated with increased Net Primary Productivity (NPP). However, continuous nitrogen loading will lead, in the long term, to changes in species composition, which may or may not be associated with increased carbon sequestration at the ecosystem level. Continuous nitrogen loading, along with other associated pollutants, could lead, in many cases, to soil acidification with a subsequent decrease in NPP. 
- Model results suggest that the combined effect of elevated $\mathrm{CO}_{2}$, higher temperatures, and nitrogen deposition is to increase nitrogen mineralization and NPP, whereas carbon storage is decreased by increasing soil temperature.

- Tropospheric ozone has negative effects on ecosystem NPP, but elevated $\mathrm{CO}_{2}$ could potentially ameliorate plant ozone injury for those species that show decreased stomatal conductance at elevated $\mathrm{CO}_{2}$. There is also the potential for increased UV-B radiation to decrease NPP.

- In general, wherever human activities have a direct, significant impact on water and nutrient cycles and on disturbance regimes, this impact will override any direct $\mathrm{CO}_{2}$ effects on ecosystem functioning.

Thus far, the work in GCTE and related programs shows that extrapolation from experiments on single plants to the responses of whole ecosystems to global change must be done with considerable care (e.g., Körner 1995). Also, $\mathrm{CO}_{2}$ will not increase independently, without other changes. In particular, temperatures and atmospheric nitrogen levels will also change, and it is the interactive effects of all three changes that we need to understand. One modeling experiment (Fig. 3) to investigate these interactive effects illustrates how important they can be and also illustrates the importance of differences in models. As research proceeds, changes in other environmental factors will become evident and will need to be included in integrated analyses.

Fig. 3. The simulated impact of double $\mathrm{CO}_{2}$, increased air temperature $\left(+2^{\circ} \mathrm{C}\right)$, and atmospheric $\mathrm{N}$ deposition $\left(+0.25 \mathrm{~g} \mathrm{x} \mathrm{m}^{-2} \times \mathrm{yr}^{-1}\right)$ on three sites: a wet Norway spruce site in Sweden (Flakiliden), a dry pine forest in Australia (BFG), and an annual grassland in California (Jasper), using the CENTURY and G'DAY models. (The G'DAY model was not run on the Jasper data).

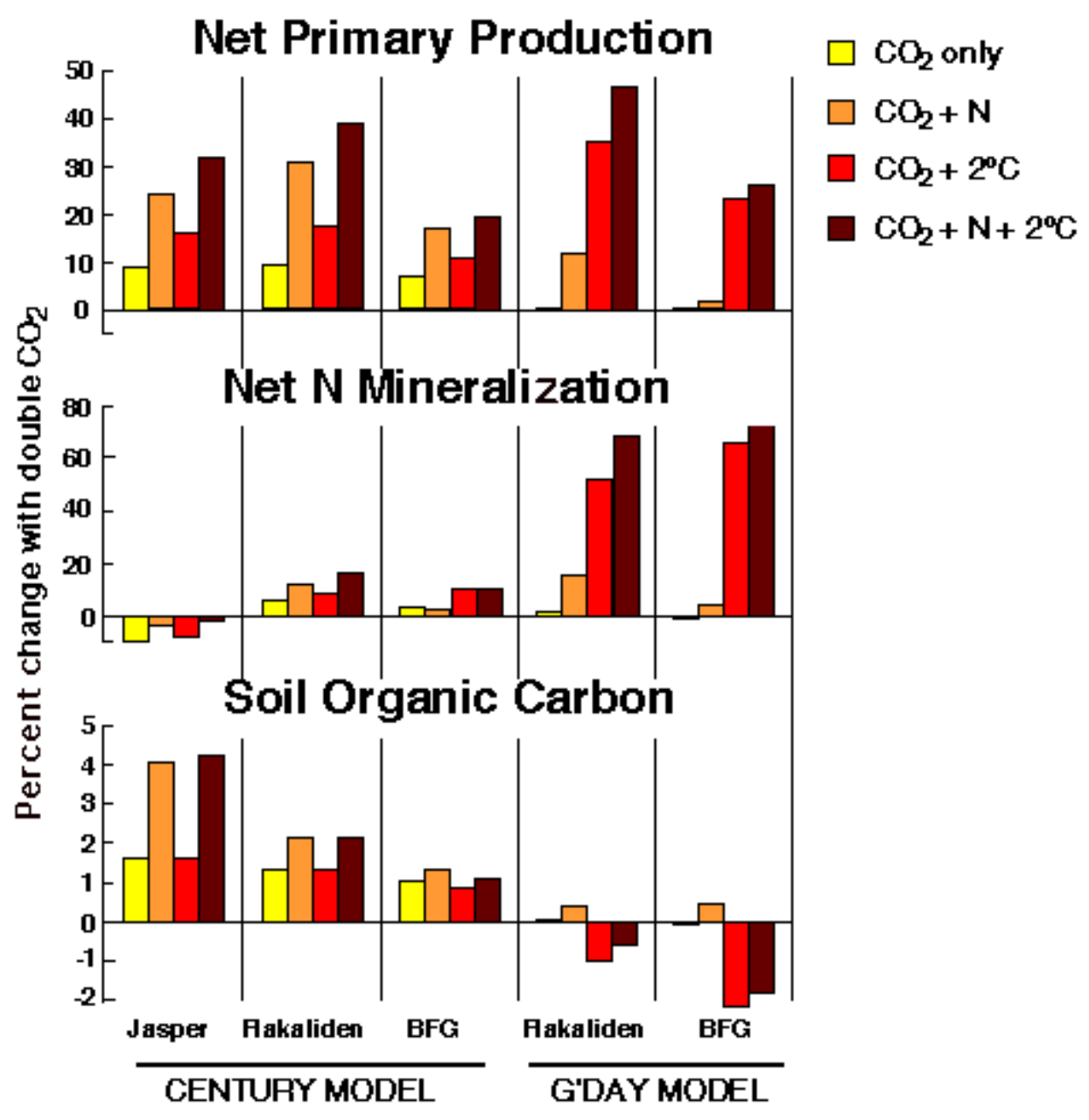

\section{Vegetation change}

First-generation models of vegetation change at regional and global scales were based on the assumption that 
vegetation is in equilibrium with its abiotic environment. These "equilibrium" models quickly found applications in a wide range of impact studies, but such use often led to a misleading concept amongst non-ecologists of vegetation change based on a rearrangement of present biomes, resulting in a sharp transition from one equilibrium distribution of biomes to another.

The reality is quite different. Impacts on vegetation composition and structure, at scales from the patch to the globe, are occurring now, are continuous, will likely accelerate, and have no identifiable or predictable end point. The understanding emerging from these nonequilibrium, transient dynamics of changing vegetation composition and structure includes several important features:

- Biomes will not shift as intact entities. Species respond differently in competitive abilities (e.g., growth rates), migration rates, recovery from (response to) disturbance, and in other ways. Thus, new combinations of species will arise.

- Paleo studies and model simulations suggest that many plant species can migrate fast enough to keep up with projected climatic change, but only if they can migrate through continuous, relatively undisturbed, natural ecosystems. This emphasises the important consequences of fragmentation of natural ecosystems as a global change phenomenon (Pitelka et al. 1997).

- Invasion of alien species into natural ecosystems is an increasing problem. It is likely to be exacerbated by trends in land use/cover change, by increased globalization of trade, and by increased disturbance.

- Disturbances (e.g., fire, dieback due to insect attacks) appear to be increasing in some regions (e.g., boreal forest), leading to more ecosystems in early successional states (Kurz et al. 1995; see Fig. 4), whereas in other regions (e.g., northern Europe), changes in management have tended to reduce the area of forests in early successional states.

- Markedly different effects of climate change on species composition will occur within individual landscapes, due to local effects of soil, land use, and topographic variation.

Fig. 4. The average area of Canadian boreal forest annually disturbed by forest fires, insect-induced stand mortality, and clear-cut logging in the period $1920-1988$ (from Kurz et al. 1995).

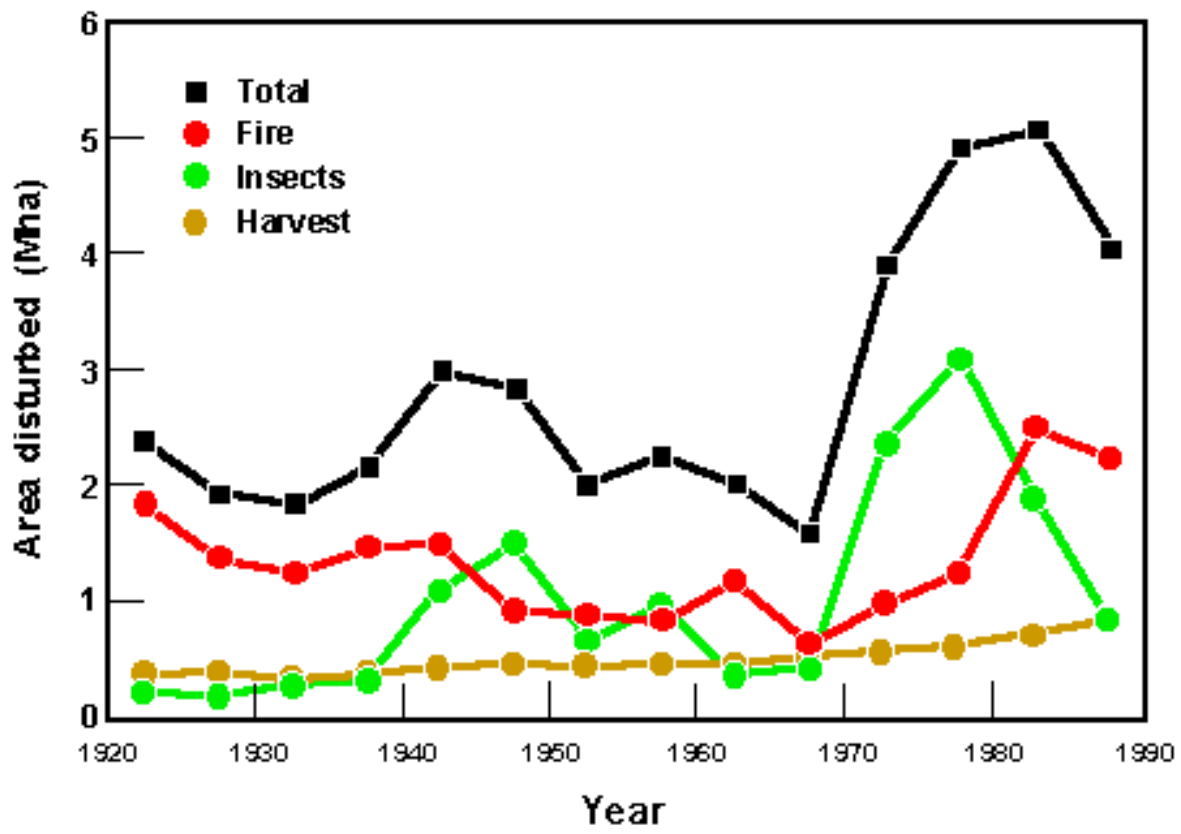

When one takes all of these factors together, some generalizations about vegetation dynamics in the 21st century begin to emerge:

- Because of changes in land use, the terrestrial biosphere of the 21 st century is likely to be further impoverished in species richness and substantially "reorganized" in species composition, with as yet unknown consequences for ecosystem functioning. 
- Disturbance and dieback will probably increase as more long-lived organisms (trees) are further from their optimal environmental envelopes and subject to increasing pressure from land use change.

- More natural ecosystems will be in an early successional state, given the projected increase in disturbance, or will be converted into human-dominated terrestrial production systems. These trends will result in a generally "weedier," structurally simpler biosphere with fewer systems in a more ecologically complex old-growth state.

\section{THE TERRESTRIAL CARBON CYCLE}

The potential for terrestrial ecosystems to absorb significant amounts of $\mathrm{CO}_{2}$, thus slowing the buildup of $\mathrm{CO}_{2}$ in the atmosphere and reducing the rate of climate change, is a key issue in the debate on $\mathrm{CO}_{2}$ emission controls. The current understanding of the global carbon cycle, based on a budget of known sources and sinks of $\mathrm{CO}_{2}$ for the1980s, is shown in Table 1.

Table 1. Average annual budget of $\mathrm{CO}_{2}$ perturbations for 1980-1989 (from Schimel 1995). Fluxes and reservoir changes of carbon are expressed in $10^{12} \mathrm{~kg} / \mathrm{yr}(=\mathrm{Gt} / \mathrm{yr})$. Numbers are from IPCC (1994), in addition to estimates for terrestrial sink terms from Schimel.

\begin{tabular}{|l|c|c|}
\hline \multicolumn{1}{|c}{$\mathbf{C O}_{2}$ budget } & $10^{12} \mathrm{~kg} / \mathrm{yr}$ & \multirow{2}{*}{ Error $^{*}$} \\
\hline $\mathbf{C O}_{2}$ sources & \multicolumn{2}{c|}{} \\
\hline Emissions from fossil fuel combustion and cement production & 5.5 & 0.5 \\
\hline Net emissions from changes in tropical land use & 1.6 & 1.0 \\
\hline Total anthropogenic emissions & 7.1 & 1.1 \\
\hline & & \\
\hline $\mathbf{C O}_{2}$ sinks & 3.2 & 0.2 \\
\hline Storage in the atmosphere & 2.0 & 0.8 \\
\hline Oceanic uptake & 0.5 & 0.5 \\
\hline Uptake by Northern Hemisphere forest regrowth & 1.0 & 0.5 \\
\hline CO 2 fertilization & 0.6 & 0.3 \\
\hline N deposition & $0.2)$ & $(2.0)$ \\
\hline Residual (source) & & \\
\hline
\end{tabular}

*Errors are accumulated by quadrature.

This analysis suggests that the terrestrial biosphere was about in balance with regard to the emission and absorption of $\mathrm{CO}_{2}$ for that period, a conclusion supported by recent measurements of atmospheric $\mathrm{O}_{2}$ concentrations (e.g., Heimann 1997). An estimated $1.6 \times 10^{12} \mathrm{~kg} / \mathrm{yr}$ (1.6 billion metric tons) of carbon were released through land use change in the tropics, whereas about $2.1 \times 10^{12} \mathrm{~kg} / \mathrm{yr}$ of carbon were absorbed by terrestrial ecosystems, through the combined effects of forest regrowth, $\mathrm{CO}_{2}$ fertilization, and nitrogen deposition. This increase in the size of some terrestrial carbon pools has been demonstrated for a number of locations, but has not been proven at a global scale or over the full vegetation disturbance cycle. It is likely that the increase is thinly distributed over a wide range of ecosystems and, thus, is hard to detect. The crucial question is whether or not this current capability of the terrestrial biosphere to absorb $\mathrm{CO}_{2}$ can be maintained or increased in the future.

Prediction of future scenarios is difficult because the terms in Table 1 cannot be projected reliably into the future. There are already large uncertainties associated with the perturbation budget of the 1980s, and even larger uncertainties would apply to specific projections for the future. However, it is possible to assess the likely trends in the terms of the budget, whether they will increase or decrease in relative importance, so that an overall trend can be projected.

\section{Land use/cover change}


As described in the Introduction, with the human population rising by about a billion per decade over the next three decades at least, sustained increases in food production of $>2 \%$ per year will be required. According to projections from the IMAGE model (Alcamo 1994) and from other analyses, this will result both in further conversion of natural ecosystems to agriculture, especially in Africa and Asia (see Fig. 5), and in intensification of production on currently cropped lands. Both of these processes almost always accelerate release of carbon to the atmosphere, so the overall rate of emission from this source will at least be maintained at current levels, or, more likely, will increase. In addition, as more land is converted to agriculture, there is less area in natural ecosystems that can act as carbon sinks, thereby reducing the potential sink strength of the terrestrial biosphere.

Fig. 5. Projection of global land cover change from 1990 to 2090 by the IMAGE 2.1 model. Colored areas depict regions projected to change from one cover type to the cover type indicated. (From R. Leemans, personal communication).

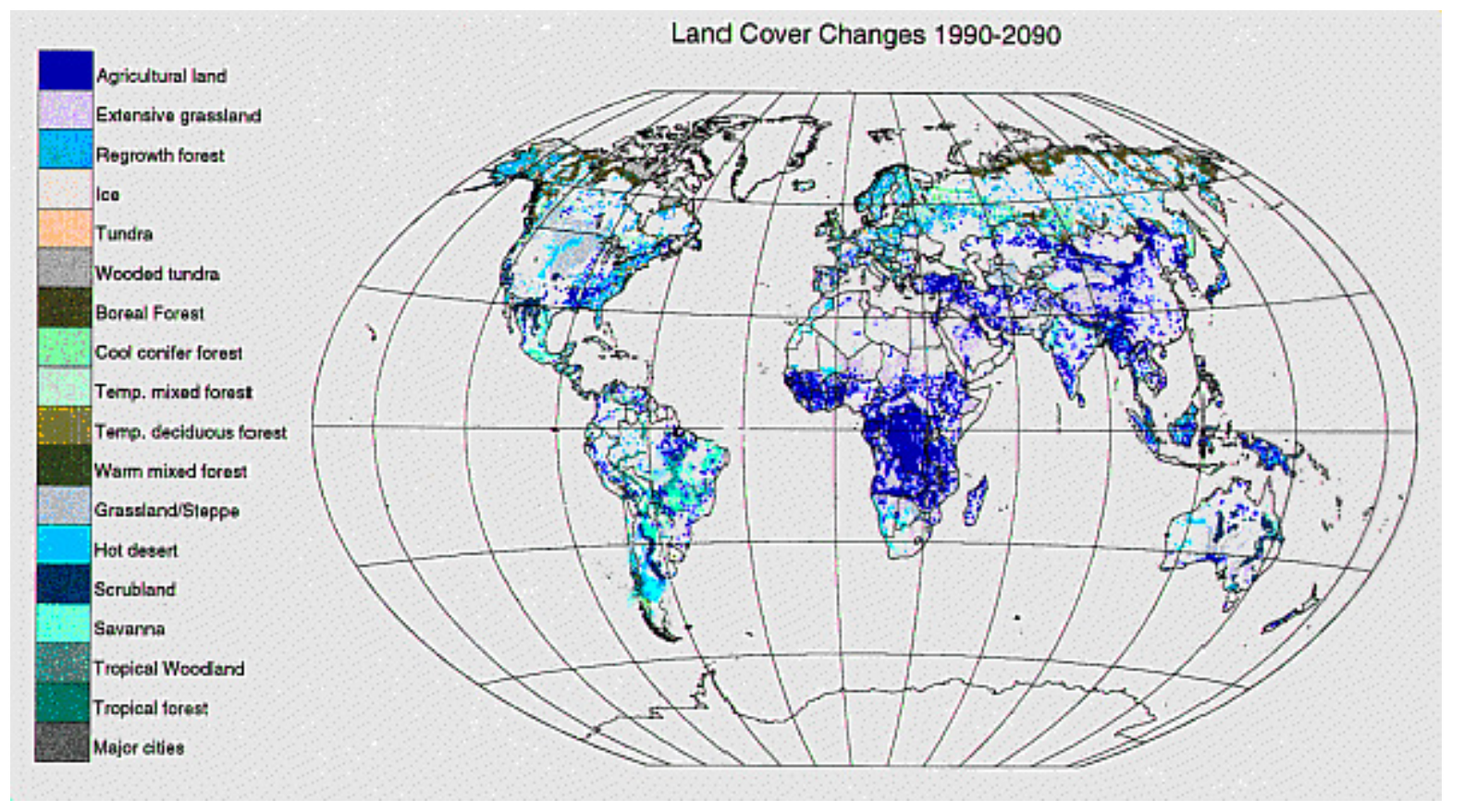

\section{Changes in ecosystem structure}

Changes in the composition and structure of ecosystems are driven by a combination of management practices (including lack of management practices) and changes in climate and atmospheric composition. For example, the biomass increases currently observed in many forested areas largely reflect successional changes due to past changes in forest management. Future global change effects will be superimposed on these present trends. In particular, the current trend of biomass increases may be reversed in some areas as the effects of global change become increasingly important. Under global change, present vegetation assemblages, rather than shifting as intact biomes, will probably change through increased mortality of some of their components, followed by establishment and growth of new assemblages. Mortality of the present vegetation, which releases carbon to the atmosphere, is a fast process, whereas the growth of a new assemblage of vegetation, which absorbs carbon from the atmosphere, is slower. Thus, the processes by which ecosystem structure and composition change will probably lead to increasing emissions of carbon to the atmosphere on a time scale of decades to centuries, irrespective of whether the new theoretical equilibrium biome distribution (assuming some stable future climate) eventually stores more or less carbon than the present distribution.

\section{Ecosystem physiology}

Specific physiological factors likely to affect the long-term carbon balance of terrestrial ecosystems include:

Soil emissions. Oxidation of soil organic matter is predicted to increase with rising temperatures. Observations from the high latitudes, where continental areas have been subjected to a temperature increase over the past three decades, suggest that some tundra ecosystems in Alaska and Siberia have gone from being carbon sinks to sources, or are in approximate balance, largely due to increasing decomposition of soil carbon. However, much more work, such as a coordinated set of warming experiments across several biomes, is required before the potential significance of soil emissions as an emerging source of $\mathrm{CO}_{2}$ can be confirmed. 
$\mathrm{CO}_{2}$ fertilization/ $\mathrm{N}$ deposition. A synthesis of the most recent ecosystem-level $\mathrm{CO}_{2}$ research indicates that the effect of $\mathrm{CO}_{2}$ on ecosystem functioning, although still potentially significant, is not as large as earlier thought. The interactive effects of land use change (abandonment of agriculture to forests), $\mathrm{N}$ deposition, and $\mathrm{CO}_{2}$ fertilization have led to strong growth in many temperate forests, with evidence that $\mathrm{N}$ deposition has played a major role (e.g., Auclair and Bedford 1995). However, the N deposition effect has a definite maximum, and it appears that it is being exceeded for some European forests (Schulze 1989).

Nutrient limitations. The carbon cycle is closely and necessarily linked, at multiple time scales, to the cycles of other nutrients, particularly nitrogen, phosphorus, and sulphur (Rastetter et al. 1997). Insufficient nutrient supply limits ecosystem-level carbon uptake and storage in many systems, thus attenuating the effects of increasing atmospheric $\mathrm{CO}_{2}$ and changing climate. In some biomes, increasing temperatures will result in increased $\mathrm{N}$ mineralization, which, on its own, would lead to enhanced $\mathrm{CO}_{2}$ uptake, at least in the short term.

Physiological "saturation." The net uptake of carbon from the atmosphere through ecosystem physiology is a balance between the assimilation of $\mathrm{CO}_{2}$ via photosynthesis and the release of $\mathrm{CO}_{2}$ through respiration and decomposition. These processes occur at different rates. Carbon assimilation responds positively and almost instantly to increased atmospheric $\mathrm{CO}_{2}$, whereas the process of decomposition responds only indirectly, through changes in temperature, moisture, and litter quality, all of which include long delay components. In addition, there are nonlinearities in these processes. Although carbon assimilation increases with increasing atmospheric $\mathrm{CO}_{2}$, it does so at a diminishing rate. Respiration, on the other hand, is an exponentially increasing function of temperature. Thus, as global change proceeds, the rate of increase of $\mathrm{CO}_{2}$ assimilation by terrestrial ecosystems will slow, while rates of both respiration and decomposition will increase. In the short term, there will be a positive effect on growth and, therefore, on $\mathrm{CO}_{2}$ uptake, but over longer time frames (centuries), the net effect will be a decrease in the ability of the terrestrial biosphere to absorb $\mathrm{CO}_{2}$.

\section{Overall trend}

The terms in the terrestrial carbon budget do not operate independently or on the same time scales, features that make it difficult to extrapolate from knowledge of the dynamics of one budget term over short time scales to long-term trends in carbon storage. The concept of Net Biome Productivity, NBP (Schulze and Heimann, in press), is a useful tool to integrate the effects of several processes over multiple time scales (Fig. 6).

Fig. 6. Terrestrial ecosystems carbon uptake and storage.

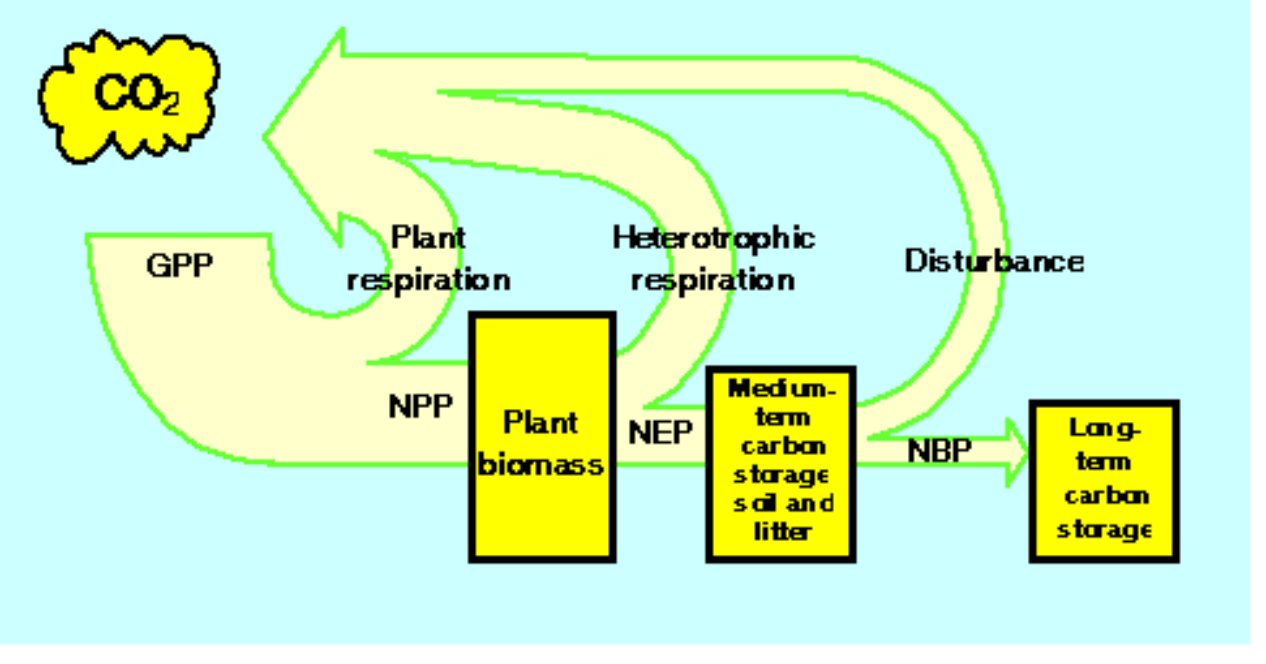

GPP, Gross primary production; NPP, Net primary production; NEP, Net ecosystem production; NBP, Net biome production.

In addition, the terms in the budget do not operate with the same strength in all regions of the world. In some regions, such as sub-Saharan Africa and large parts of Asia, the land use change component is likely to dominate, and these regions will be net sources of carbon. For others, such as parts of North America and Europe, the carbon 
sequestration processes may dominate and these regions may remain, or become, significant carbon sinks on a decadal or century time frame.

Given the difficulty in estimating the future (or even present) magnitudes of processes that sequester carbon (e.g., $\mathrm{N}$ deposition, $\mathrm{CO}_{2}$ fertilization) vs. those that release carbon (soil organic matter oxidation, ecosystem structural change), there are many possible scenarios for the terrestrial carbon cycle at a global scale over the next 100 years. However, there is little doubt that, for the next several decades at least, more areas of natural ecosystems will be converted to agriculture, simultaneously emitting carbon and reducing the amount of land on which significant amounts of carbon can be sequestered. Thus, the overall conclusion of the GCTE synthesis is that the present rate of absorption of carbon from the atmosphere, on a global scale, will be difficult to maintain. It is more likely that the terrestrial biosphere as a whole (that is, including land converted or modified for production of food and fiber) will become a net source. This projection has significant implications for the development of strategies to stabilize the concentration of greenhouse gases in the atmosphere.

\section{LIVING WITH GLOBAL CHANGE}

\section{Managed production systems}

The need to meet a $2 \%$ per annum or greater increase in food demand will put enormous stresses on managed production systems. Climatic change will probably further stress these systems. Extreme weather events, such as back-to-back droughts in one, or simultaneous droughts in two or more, of the world's major grain-producing areas would create severe food shortages. (The extended drought in the mid-U.S. grain region in the 1930s caused massive environmental and economic damage).

One response to the food supply issue is technology: the development of improved cropping systems and/or crop varieties. There is no doubt that improved varieties, such as genetically engineered crops with in-built insecticides and short-season varieties with high water use efficiencies, will offset some of the increased demand. However, biotechnology has not yet succeeded in improving our capability to cope with complex, system-level problems such as drought and salinity. A sustained increase in global production of the required $2 \%$ per year will almost surely be achieved, but it will have considerable impact on land use and on ecosystems in general. Climate change makes the task of producing the additional food and fiber more uncertain.

The availability of resources will continue to constrain agricultural development in many regions. For example, water availability, already a major problem, is likely to become increasingly limiting as agricultural, industrial, and urban demands for water compete more directly with the need to maintain river flows for conservation and waste removal and purification purposes.

In terms of the impacts of global change on terrestrial production systems, and the implications for regional and global food supply, work over the past six years has highlighted the following major issues:

- Crop production. Crop production will be affected very differently in different parts of the world (as already highlighted by other recent assessments). Recent estimates indicate increases in yield at mid and high latitudes, but decreases at low latitudes, where food demand will be greatest.

Under ideal field conditions, wheat yields are unlikely to increase by more than about $10 \%$ for a doubled current $\mathrm{CO}_{2}$ concentration; a 5-7\% increase is more realistic for average management conditions (Pinter et al. 1996). Major wheat models are being rapidly refined, but caution is still needed in spatial extrapolation using any single model (see Table 2).

Table 2. Maximum and minimum estimates of wheat yield ( $1 \mathrm{Mg}=1$ metric ton) by eight models from the GCTE Wheat Network. Models simulated the growth of hypothetical wheat crops using common weather data sets and the same time course of leaf area index (LAI) development. (From Goudriaan et al. 1994).

\begin{tabular}{|l|c|c|c|c|c|}
\hline & $\begin{array}{c}\text { Day of year of } \\
\text { anthesis }\end{array}$ & $\begin{array}{c}\text { Day of year of } \\
\text { maturity }\end{array}$ & $\begin{array}{c}\text { LAI } \\
\left(\mathrm{m}^{2} / \mathrm{m}^{2}\right)\end{array}$ & $\begin{array}{c}\text { Grain dry } \\
\text { mass } \\
(\mathrm{Mg} / \mathrm{ha})\end{array}$ \\
\hline \multicolumn{3}{|c|}{\begin{tabular}{c|c|c|} 
Crookston, Minnesota, USA (spring wheat) \\
$(\mathrm{Mg} / \mathrm{ha})$
\end{tabular}} \\
\hline Prescribed & 183 & 216 & 4.5 & 10.6 \\
\hline Minimum & 182 & 215 & 4.5 & 16.1 \\
\hline Maximum & 187 & 216 & 8.6 \\
\hline
\end{tabular}




\begin{tabular}{|l|l|l|l|l|l|}
\hline \multicolumn{2}{|c|}{} & \multicolumn{3}{|c|}{ Lelystad, The Netherlands (winter wheat) } \\
\hline Prescribed & 166 & 207 & 7.5 & 13.5 & \\
\hline Minimum & 164 & 204 & 7.5 & 26.4 & 12.1 \\
\hline Maximum & 166 & 207 & & \\
\hline
\end{tabular}

Temperatures $>32^{\circ} \mathrm{C}$ reduce rice yields due to spikelet sterility. This relationship is unaffected by elevated $\mathrm{CO}_{2}$. Major rice models agree across a wide range of potential yields and suggest about a $5 \%$ reduction in yield per $1^{\circ} \mathrm{C}$ rise for temperatures $>32^{\circ} \mathrm{C}$ (see Fig. 7).

Fig. 7. Relative changes in rice yield due to changes in temperature, as simulated by five growth models. (From Mitchell 1996).

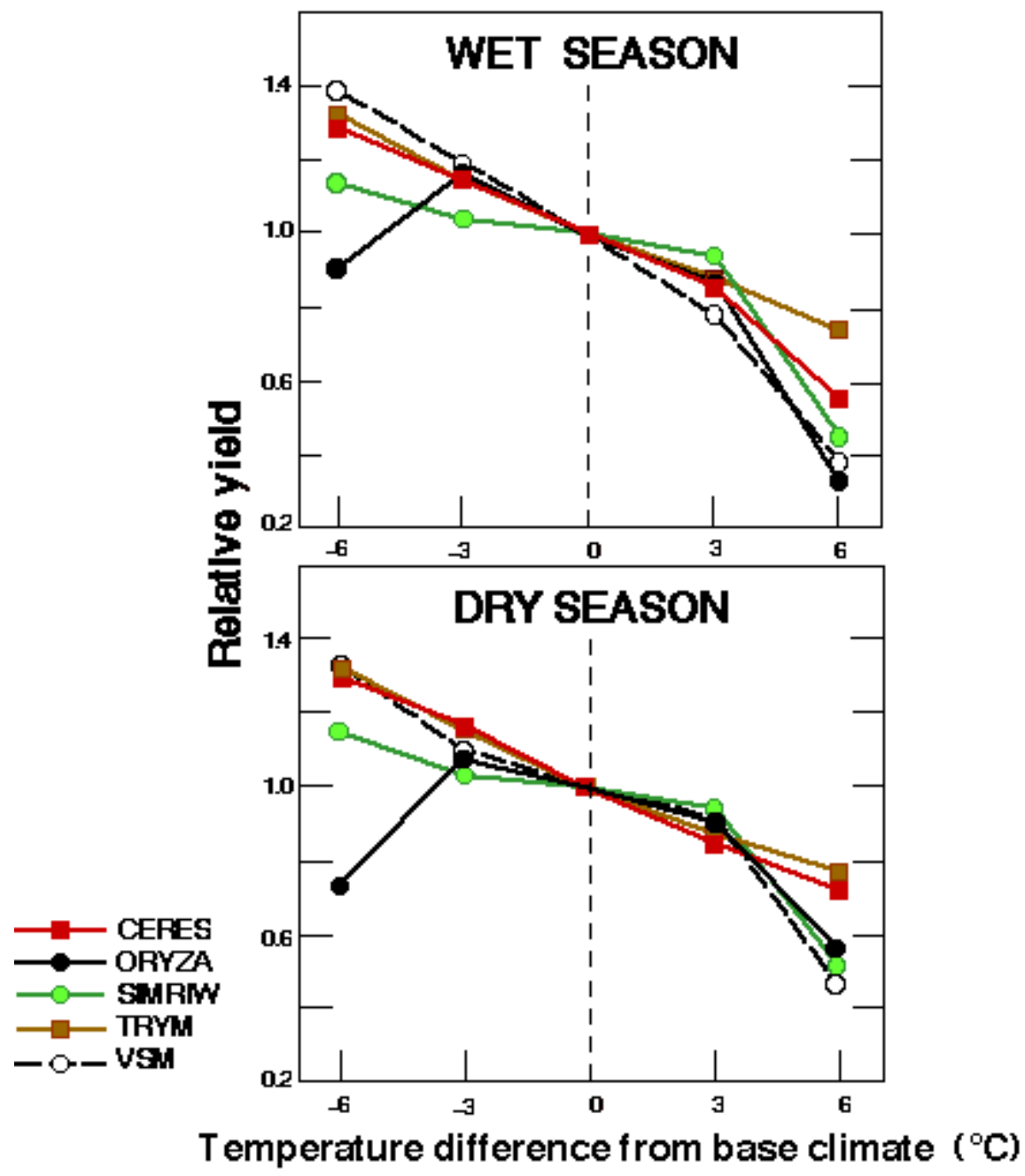

Pests, diseases, and weeds currently cause losses of between one-third and one-half of crop production. Climate change is likely to cause a spread of tropical and subtropical species into temperate areas and to increase the activities of species currently limited by thermal accumulation at higher latitudes.

- Pastures and rangelands. The crop/rangeland boundary will encroach on grazing lands in developing countries due primarily to population pressure. Changes in rangeland livestock production will be dominated by a reduction in land area due to cropping and to changes in evapotranspiration and precipitation. A doubling of current $\mathrm{CO}_{2}$ will increase production in different pastures and rangelands by $0 \%$ to $20 \%$, depending on emperature, water, and nutrient limitations. A sensitivity analysis for one subtropical pasture indicated that a $5 \%$ increase in pasture growth due to $\mathrm{CO}_{2}$ would lead to a $3 \%$ increase in long-term mean liveweight gain in cattle by reducing the variability of NPP between years.

- Managed forests. Short-term studies of elevated $\mathrm{CO}_{2}$ in managed forests show an increase in plant biomass 
production by young trees grown under fertile conditions. This increase, however, will be reduced in the longer term as an effect of increased net ecosystem respiration. This reduction may be substantially compensated for by interactive effects of $\mathrm{CO}_{2}$ and atmospheric nitrogen deposition; the net effect is uncertain.

-Soils. The main control on soil organic matter (SOM) levels and erosion over the next few decades will continue to be land management, but changes in vegetation cover due to near-term changes in climate variability will be significant, especially in semiarid regions. A longer term increase in mean temperatures will accelerate SOM oxidation, especially where it allows new land to be brought into cultivation. Soil erosion increases linearly with mean precipitation, but nonlinearly with wind speed, with a threshold for rapid and significant increase in wind erosion at about $5.5 \mathrm{~m} / \mathrm{s}$ (see Fig. 8).

Fig. 8. Sensitivity of soil erosion in the U.S. corn belt to climate change, as estimated using the model EPIC. Each point represents the 100-yr average of 100 randomly selected sites.

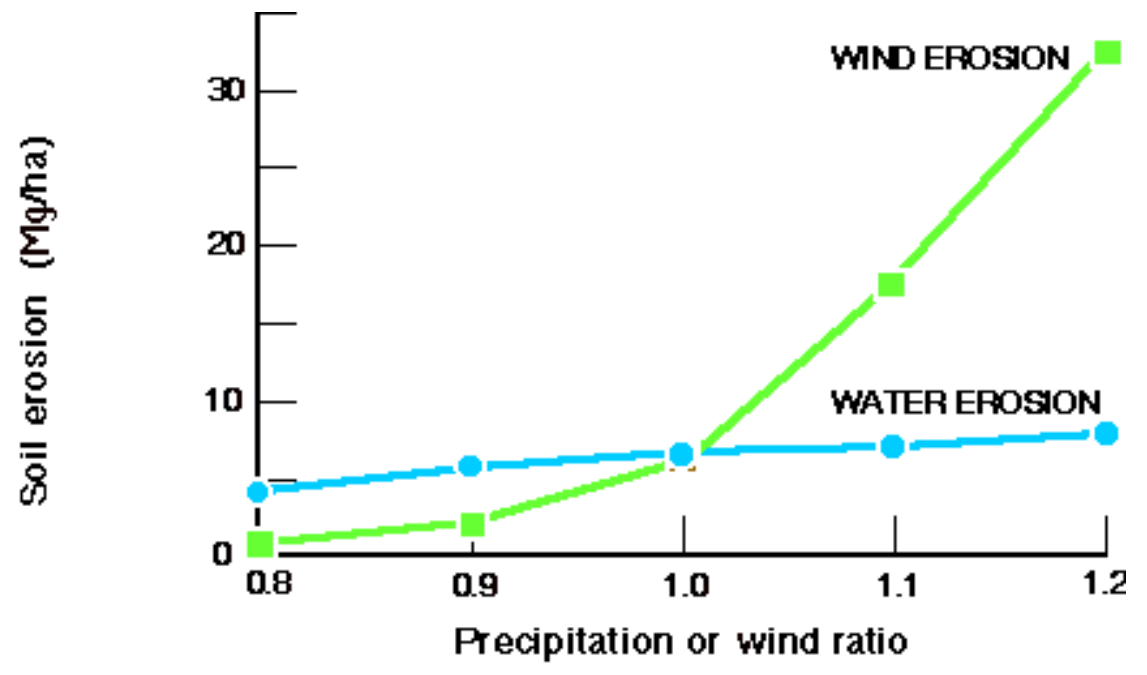

\section{Biodiversity}

A strong consensus emerging from a recent analysis of future biodiversity trends in the major biomes of the world (Sala and Chapin, in preparation) identified the main cause of biodiversity loss in the coming decades as land use change, mainly loss of habitat and landscape fragmentation. The next most important factor identified was invasion by alien species. Although trends are less certain here, the general conclusion is that alien species will be an increasing problem, given (1) the globalization of economies and, hence, the movement of people and materials; and (2) the susceptibility of disturbed ecosystems to invasions. Changes in atmospheric composition and climate are regarded as longer term factors, increasing in relative importance over time. However, changes in $\mathrm{N}$ deposition have important impacts in shorter time frames on species diversity, particularly in plants, especially in the developed world.

\section{CONCLUDING COMMENT}

Global change is occurring now, will continue for the foreseeable future, and is likely to intensify in many aspects. It is an emerging reality that will increasingly impact on the political process, on regional strategic planning, and on the daily lives of resource managers. Learning to live with global change, to avoid the worst hazards and capitalize on opportunities as they arise, requires creative and innovative strategies. These must be built upon a sound, scientific understanding of terrestrial ecosystem interactions with global change.

How can, or should, society use current scientific understanding in responding to global change? An example of this difficulty is the current debate on the "take action now vs. take action later (or take no action)" proposals to limit greenhouse gas emissions. Some global processes have lag times of decades or even centuries. Thus, the consequences of taking no action now may not be felt until the middle of next century, but when these consequences do occur, they could be serious and very difficult to cope with. An example of such a lag effect is the diminishing ability of the terrestrial biosphere to absorb carbon as both atmospheric $\mathrm{CO}_{2}$ concentrations and temperatures increase. A lack of action now could lead to a large, unavoidable, additional $\mathrm{CO}_{2}$ release a century or so from now, through increasing decomposition of soil organic matter (about twice as much carbon is stored below ground than above in terrestrial ecosystems). 
The bottom line is that we will probably never be able to predict, with a high degree of certainty, precisely how terrestrial ecosystems will interact with accelerating environmental change. Thus, the analogy that ecosystems can be "managed" in the same way that much simpler human-designed industrial systems can, is misleading and dangerous. In terms of terrestrial ecosystem interactions with global change, we must expect the unexpected (and unpredictable) and keep open as many response options as possible. There is an inescapable trade-off between resilience and production in agro-ecosystems: the most productive systems are often the simplest, but they are the least resilient to disturbance and perturbation. Highly productive systems are required to feed an expanding population; complex, resilient systems are required to be able to respond to future shocks and disturbances, and to continue providing the ecosystem "goods and services" we need.

\section{RESPONSES TO THIS ARTICLE}

Responses to this article are invited. If accepted for publication, your response will be hyperlinked to the article. To submit a comment, follow this link. To read comments already accepted, follow this link.

\section{Acknowledgments}

This is an overview of a detailed synthesis of the past six years' work of the Global Change and Terrestrial Ecosystems (GCTE) Project of the International Geosphere-Biosphere Programme (IGBP). The full synthesis, which will be published by Cambridge University Press in early 1998, was written by over thirty GCTE scientists. The authors of this paper have prepared the overview from an Executive Summary of the Synthesis, distributed by the IGBP Secretariat in Stockholm, in December 1997.

We thank the German National IGBP Secretariat and the National Center for Ecological Analysis and Synthesis in Santa Barbara, California, for their generous financial support for the two GCTE synthesis workshops in 1996.

\section{LITERATURE CITED}

Alcamo, J., editor. 1994. IMAGE 2.0: Integrated modeling of global climate change. Kluwer Academic Publishers, Dordrecht, The Netherlands.

Auclair, A.N.D., and J.A. Bedford. 1995. Recent shifts of annual net forest volume balance in boreal forest, and its implications for global carbon balance. Ecosystems Research Report 10, European Commission, Brussels, Luxembourg.

Goudriaan, J., S.C. van de Geijn, and J.S.I. Ingram. 1994. GCTE Focus 3 Wheat modelling and experimental data comparison workshop report. GCTE Focus 3 Office, Oxford, UK.

Heimann, M. 1997. A review of the contemporary global carbon cycle as seen a century ago by Arrhenius and Hogbom. Ambio 26: 17-24.

IPCC WGI. 1995. Climate Change 1995 - The science of climate change. Contribution of Working Group I to the Second Assessment Report of the Intergovernmental Panel on Climate Change. J.T. Houghton, L.G. Meira Filho, B.A.Callander, N.Harris, A. Kattenberg, and K. Maskell editors. Cambridge University Press, Cambridge, UK.

Körner, Ch. 1995. Towards a better experimental basis for upscaling plant responses to elevated $\mathrm{CO}_{2}$ and climate warming. Plant, Cell, and Environment 18: 1101-1110.

Kurz, W.A., M.J. Apps, S.J. Beukema, and T. Lekstrum. 1995. 20th century carbon budget of Canadian forests. Tellus 47B: 170-177.

Mitchell, P.L. 1996. Comparison of five models of rice yield showing the efects of change in temperature and in carbon dioxide concentration. In J.S.I. Ingram, editor. Report of the GCTE Rice Network Experimentation Planning Workshop. GCTE Working Document 19.

Pinter, P.J. Jr., B.A. Kimball, R.L. Garcia, G.W. Wall, D.J. Hunsaker, and R.L. LaMorte. 1996. Free-air $\mathrm{CO}_{2}$ enrichment: responses of cotton and wheat crops. Pages 215-249 in G.W. Koch and H. A. Mooney, editors. Carbon dioxide and terrestrial ecosystems. Academic Press, San Diego, California, USA.

Pitelka, L.F. and Plant Migration Workshop Group. 1997. Plant migration and climate change. American Scientist 85: 464-473. 
Rastetter, E.B., G.I. Ågren, and G.R. Shaver. 1997. Responses of N-limited ecosystems to increased $\mathrm{CO}_{2}:$ a balanced-nutrition, coupled-element-cycles model. Ecological Applications 7: 444-460.

Sala, O.E., and F.S. Chapin, III, editors. Future scenarios of biodiversity loss. Springer-Verlag, Heidelberg, Germany, in press.

Schimel, D.S. 1995. Terrestrial ecosytems and the carbon cycle. Global Change Biology 1:77-91.

Schulze, E-D. 1989. Air pollution and forest decline in a spruce (Picea abies) forest. Science 244: 776-783.

Schulze, E-D., and M. Heimann. Carbon and water exchange of terrestrial ecosystems. In J.N. Galloway and J.M. Melillo, editors. Asian change in the context of global change. IGBP Book Series Number 3, Cambridge University Press, Cambridge, UK, in press..

Walker, B.H., W.L. Steffen, J. Canadell, and J.S.I. Ingram, editors. Implications of global change for natural and managed ecosystems: a synthesis of GCTE and related research. IGBP Book Series Number 4, Cambridge University Press, Cambridge, UK, in press.

\section{Address of Correspondent:}

Brian Walker

CSIRO Wildlife and Ecology, and

GCTE Core Project Office

Bellenden Road, Gungalin ACT 2600

phone: $61-02-6242-1742$

fax: 61-02-241-2362

Brian.Walker@dwe.csiro.au

*The copyright to this article passed from the Ecological Society of America to the Resilience Alliance on 1 January 2000. 